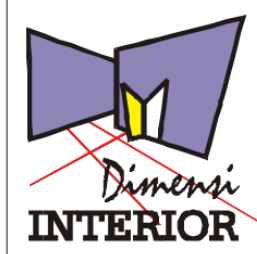

http://dimensiinterior petra.acid

\title{
Perancangan Omahub! Apartemen Small Office Home Office Multifungsi
}

\author{
Melissa Ardani ${ }^{1}$ | Natasya Angelina ${ }^{1}$ | Filipius Priyo Suprobo, S. T. ${ }^{2}$ \\ 1 Program Studi Desain Interior, Universitas Kristen Petra, Surabaya \\ 2 Program Studi Arsitektur, Universitas Widya Kartika, Surabaya \\ Email: melissardani@gmail.com
}

\begin{abstract}
ABSTRAK
Hunian merupakan salah satu kebutuhan primer tiap manusia, di mana manusia melakukan banyak aktivitas di dalamnya. Dewasa ini dengan bertambahnya populasi manusia yang terus menerus dengan lahan yang semakin sedikit menimbulkan alternatif hunian bertingkat yaitu apartemen. Apartemen merupakan hunian yang memiliki lahan kecil sehingga tidak semua aktivitas dapat dilakukan di dalamnya. Sehingga small office home office yang merupakan gabungan fungsi kantor dan rumah menjadi solusi baik untuk fenomena ini. Perancangan Omahub sebagai solusi yang berkonsep menjadikan suatu apartmen menjadi pusat $(h u b)$ area profesional muda untuk melakukan segala kegiatannya baik sebagai rumah dan workspace dalam sehari-hari.
\end{abstract}

Kata Kunci: small office home office, apartemen, multifungsi, interior

\begin{abstract}
Occupancy is one of the primary needs of every human being, where humans do many activities in it. Today, with the increasing human population that continues to increase with less and less land producing multilevel residential alternatives, namely apartments. The apartment is a residence that has small land. There is no process that can be done in it. a small office home office that is a functioning office and home. The design of Omahub is a solution that is designed as a hub (area) of young professional areas to carry out various activities both as a home and work space in everyday life.
\end{abstract}

Keywords: small office home office, apartement, multifunction, interior

\section{PENDAHULUAN}

Sayembara Dulux Designer Award merupakan sebuah ajang tahunan yang diadakan oleh PT. Akzonobel yang bekerjasama dengan HDII Jakarta. Sayembara desain ini bertujuan untuk menggali potensi para Arsitek dan Desainer Interior Indonesia, dan untuk menunjukan reputasi terutama Desainer Muda Indonesia yang unggul dan terkemuka di skala Internasional. Selain itu, untuk mewujudkan semangat dan menciptakan tren lokal di masyarakat, khususnya di Indonesia.

Pada tahun 2017, sayembara ini mengangkat tema besar lomba mengenai SOHO yang diangkat berdasarkan permasalahan dan kondisi Indonesia kedepannya. SOHO berasal dan kata small office home office. Sebuah bangunan dengan fungsi ganda. Seiring dengan bertambahnya penduduk dan mahalnya lahan di perkotaan, SOHO menjadi alternatif paling strategis bagi keluarga muda dan Profesional muda di kota besar saat ini. Berdasarkan data pada tahun 2017, Perserikatan Bangsa-Bangsa atau PBB menyatakan, jumlah penduduk dunia saat ini tercatat sebanyak 7,6 miliar dan akan melonjak menjadi 9,8 miliar pada tahun 2050. Laporan yang disusun oleh Departemen Populasi Divisi Urusan Sosial dan Ekonomi PBB pada Rabu, 21 Juni 2017, memperkirakan bahwa populasi dunia saat ini mencapai hampir 7,6 miliar akan meningkat menjadi 8,6 miliar pada tahun 2030, 9,8 miliar pada tahun 2050 dan 11,2 miliar pada tahun 2100.Dan Pertumbuhan populasi sebanyak 90\% di kota besar sudah terjadi setiap tahunnya dan berbagai upaya untuk meminimalisir penggunaan lahan semakin ditingkatkan [1]. Melalui data tersebut dapat disimpulkan semakin tahun jumlah populasi manusia di dunia semakin meningkat dan terus berkembang semakin banyak.

Fenomena meningkatnya populasi manusia yang pesat, membuat kebutuhan tempat tinggal juga meningkat. Melalui fakta yang ada, pertumbuhan populasi manusia dengan luas lahan untuk tempat tinggal tidak berbanding 
lurus. Semakin tahun lahan hunian semakin sedikit dan mahal. Sehingga dewasa ini, terutama di Surabaya dapat dilihat pembangunan hunian vertikal/bertingkat semakin marak untuk menanggapi fenomena tersebut. Semakin banyak pembangunan apartemen juga tidak langsung menyelesaikan masalah, banyak masalah baru timbul karena apartemen yang lebih cenderung kecil dengan aktivitas manusia yang tetap sama.

Small Office Home Office (SOHO) adalah sebuah hunian (Apartemen ataupun Rumah), yang didalamnya dilengkapi berbagai macam fasilitas kantor. Secara legal fungsi tersebut mendapatkan izin guna dari pemerintah kota sebagai hunian yang sekaligus tempat usaha, dalam hal ini fungsi kantor. Menjadi salah satu solusi untuk menjawab permasalahan untuk memanfaatkan lahan kecil apartemen yang dapat menampung aktivitas manusia yang beragam dan banyak. SOHO merupakan konsep hunian yang menggabungkan antara rumah tinggal atau apartemen dengan workspace. Tujuan dari perancangan ini adalah membuat manusia tetap nyaman beraktivitas dengan lahan yang kecil, dan user di dalamnya bisa nyaman.

\section{LANDASAN TEORI}

\section{Apartemen}

Apartemen adalah bangunan tempat tinggal bertingkat yang mencakup berbagai fasilitas [3]. Biasanya, satu unit apartemen terdiri atas ruang duduk, kamar tidur, pantry, kamar mandi, dan ruang tambahan lain jika unit yang dimiliki memiliki ukuran yang lebih besar[4]. Apartemen dibangun sebagai solusi atas kepadatan hunian pribadi dan keterbatasan lahan dengan harga yang terjangkau di perkotaan. [5]

\section{Small Office Home Office}

Home office merupakan istilah yang berhubungan dengan bisnis atau usaha kecil yang dilakukan di rumah. Home office menjadi populer karena semakin tinggnya mobilitas namun waktu dan jarak semakin terbatas untuk melakukan usaha [6]. Dual Purposed Office merupakan salah satu jenis home office. Biasanya jenis ini dijumpai pada rumah tinggal atau apartemen dengan memberi pemisah antara ruang privasi dengan ruang umum. [7]

\section{Multifungsi}

Dalam Kamus Besar Bahasa Indonesia (2008: 560), multifungsi merupakan sesuatu yang mempunyai berbagai tugas atau fungsi. Dapat diartikan ruang multifungsi merupakan ruang yang memiliki lebih dari 1 fungsi dalam satu waktu. Ruang multifungsi memiliki nilai lebih, hal ini karena biasanya bisa menghemat luas tanah, waktu, dan mempermudah kerja manusia. Begitu pula dengan furnitur multifungsi yang memiliki nilai lebih dari segi ekonomi dan ergonomi. Furnitur jenis ini cocok untuk ruangan yang sempit seperti apartemen tipe studio, rumah dengan tipe rumah sederhana[8].

\section{Teknologi}

Castells (2004) menyebutkan bahwa teknologi merupakan suatu kumpulan alat, aturan dan juga prosedur yang merupakan penerapan dari sebuah pengetahuan ilmiah terhadap sebuah pekerjaan tertentu dalam suatu kondisi yang dapat memungkinkan terjadinya pengulangan.[9] Pendapat lainnya mengenai pengertian teknologi diungkapkan oleh Miarso (2007) yang mengungkapkan bahwa teknologi merupakan suatu bentuk proses yang meningkatkan nilai tambah. Proses yang berjalan tersebut dapat menggunakan atau menghasilkan produk tertentu, dimana produk yang dihasilkan tidak terpisah dari produk lain yang telah ada. Lebih lanjut disebutkan pula bahwa teknologi merupakan suatu bagian dari sebuah integral yang terdapat di dalam suatu sistem tertentu.[10]

\section{METODE PERANCANGAN}

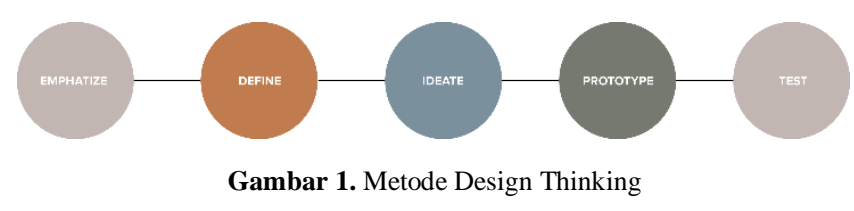

\section{Emphatize}

Pada tahapan emphatize, pertama kali yang dilakukan tim adalah melakukan wawancara untuk memahami kebutuhan pengguna apartemen. Wawancara dimulai untuk mencari permasalahan yang ada pada pengguna apartemen dan kepada orang yang masih tinggal di rumah biasa untuk mengetahui barrier. Selanjutnya dilakukan eksplorasi lapangan di salah satu unit apartemen tipe studio di Surabaya yang bertujuan mengetahui variasi interior apartemen di Surabaya. Selain itu, dilakukan analisis tipologi mengenai small office home office dan teknologi pada hunian.

\section{Define}

Hasil eksplorasi dan wawancara dianalisa untuk memahami kebutuhan ruang, pola tingkah laku, dan pola sirkulasi ruang. Sehingga, melalui proses itu rumusan masalah yang harus diselesaikan dapat ditemukan dan juga menemukan goals yang ingin dicapai apa dari hasil wawancara.

\section{Ideate}

Pada tahap ini dilakukan penyusunan desain konsep dan skematik desain agar pemanfaatan ruang menjadi lebih maksimal dan nyaman untuk penghuni apartemen. Proses ideate juga menggunakan metode brainstroming antara anggota tim, proses brainstorming dilakukan beberapa tahap hingga juga melibatkan dosen pembimbing untuk memberi masukan kepada perancangan. Melalui brainstroming dengan dosen pembimbing, tim menambahkan fitur teknologi ditambahkan untuk memaksimalkan nilai guna ruang.

\section{Prototype}

Perancangan desain dari alternatif ide-ide SOHO kemudian dibuat dengan 3D modelling. Tahap prototype ini bertujuan untuk melihat kelebihan dan kekurangan desain untuk diperbaiki selanjutnya. Proses 3D modelling membuat tim dapat menambahkan kekurangan dari fasilitas ruang dan memunculkan ide-ide yang baru.

\section{Test}

Hasil akhir dari perancangan kemudian di submit pada ajang Dulux Designer Awards 2017 yang diadakan oleh PT. Akzonobel yang bekerja sama dengan HDII Jakarta. 
Kemudian perancangan ini masuk 5 besar dalam kategori mahasiswa. Kemudian dilakukan penjurian karya yang beranggotakan juri Diana Nazir,HDII (interior designer), Tika Bisono (psikolog), Mario Tetelepta (Designer/Branding), Anastasia Tirtabudi (Dulux Representative) dan Chairul Amal (interior designer). Pada tahap penjurian para dewan juri memberikan umpan balik sekaligus apresiasi, diantaranya masukan agar menentukan satu nilai jual yang utama dan apresiasi mengenai konsep desain "omah"dan "hub".

Dari seluruh tahapan metode design thinking ini, para penulis meyakini bahwa tahapan ini adalah yang paling efektif untuk dikembangkan. Hal tersebut terutama dalam konteks ikut merasakan sebagai user, bekerjasama secara tim, enjoy dalam kerja dan penuh passion/hasrat. [11]

\section{DESKRIPSI DESAIN}

Perancangan Omahub sebagai solusi, berkonsep untuk menjadikan suatu apartemen menjadi pusat $(h u b)$ area profesional muda untuk melakukan segala kegiatannya baik sebagai rumah dan workspace dalam sehari-hari. Selain dwifungsi, Omahub! berkonsep merubah streotype apartemen dengan luasan yang kecil,

terkesan sesak, dan tidak dapat melakukan segala aktivitas dengan leluasa sehingga merasa bukan sebuah rumah. Omahub! membuat sebuah apartemen yang memiliki suasana omah (homey), kesan homey yang nyaman, menyenangkan, dan mudah dirindukan dapat dirasakan oleh penghuni. Omahub! juga ingin menjadi sebuah workspace untuk profesional muda yang memiliki jiwa muda dengan semangat untuk berkarya terus menerus memiliki pemikiran kreatif sehingga Omahub menjadi tempat bekerja nyaman, meningkatkan produktivitas dan workspace ini dapat untuk berkolaborasi antar individu. produktivitas bekerja juga didukung dengan teknologi dan multifungsi Omahub tersebut.

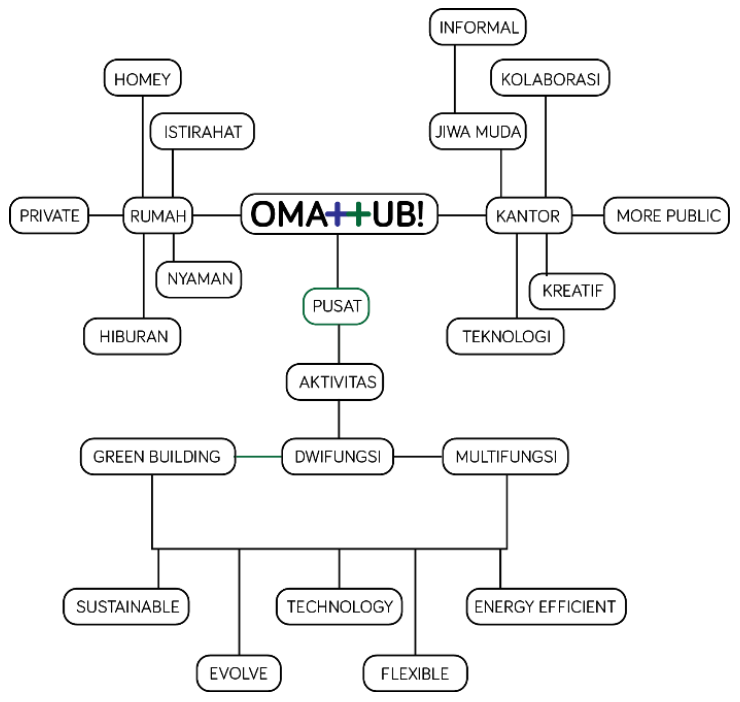

Gambar 2. Mindmapping Konsep Awal Perancangan

\section{HASIL DAN PEMBAHASAN}

\section{Layout Perancangan}

Layout dari small office home office sangat flexible dapat mengikuti kebutuhan aktivitas pengguna sehingga dapat berubah dari ruang tidur hingga untuk bekerja.
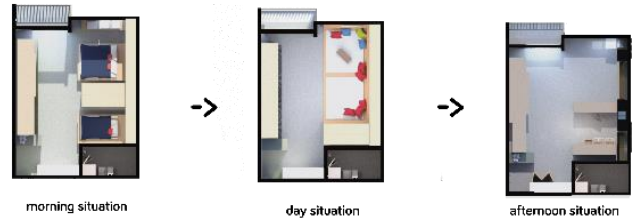

Gambar 3. Layout Ruangan dengan Fungsi yang Berbeda
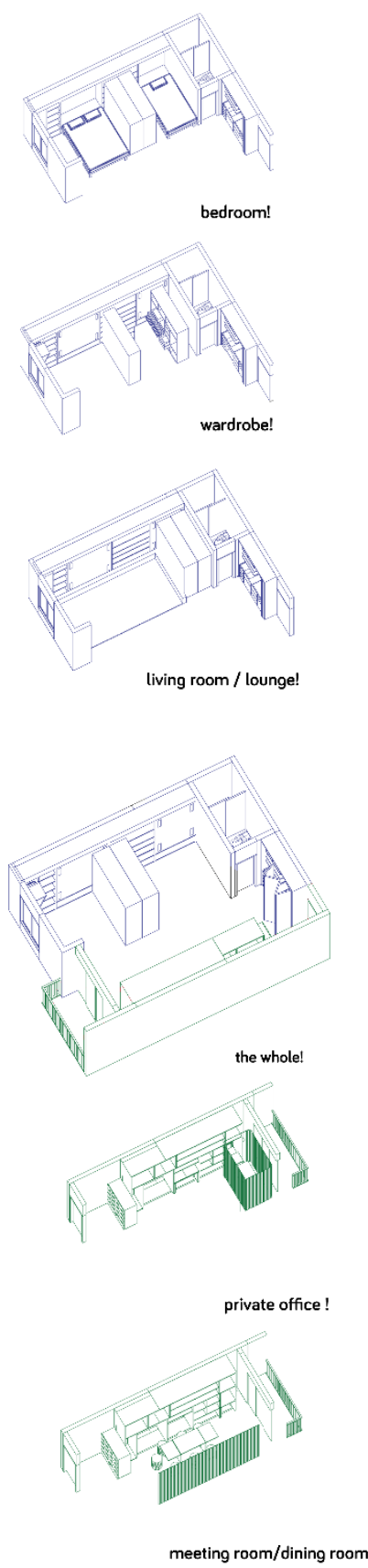

Gambar 4 Isometri Ruangan 


\section{Perspektif}

1. Mode Ruang Tidur

Multifunction bed, kasur dapat di naik turunkan sehingga ketika bekerja mendapatkan space lebih besar.

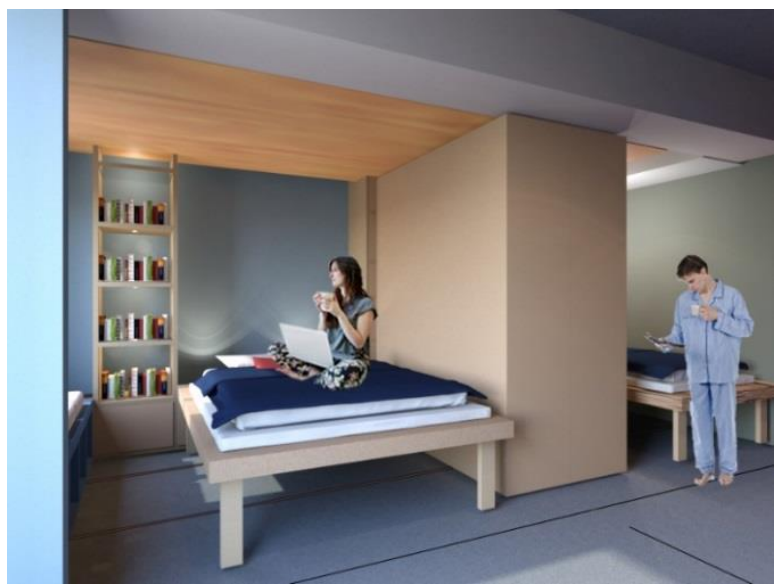

Gambar 5. Perspektif Ruang Tidur.

2. Mode Lemari Pakaian

Private wardrobe, ketika ranjang diangkat. Lemari dapat menjadi sebuah wardrobe berganti baju dan berdandan.

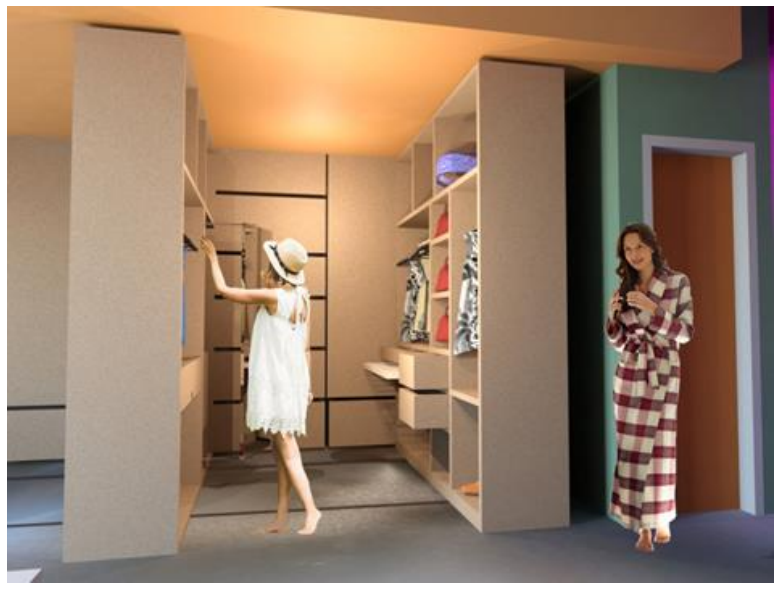

Gambar 6. Perspektif Wardrobe Area

3. Mode Bekerja

The smart table, meja yang bisa keluar dengan teknologi gesture. dan juga dapat diexpand muat untuk 2-6 orang. dapat digunakan untuk meeting

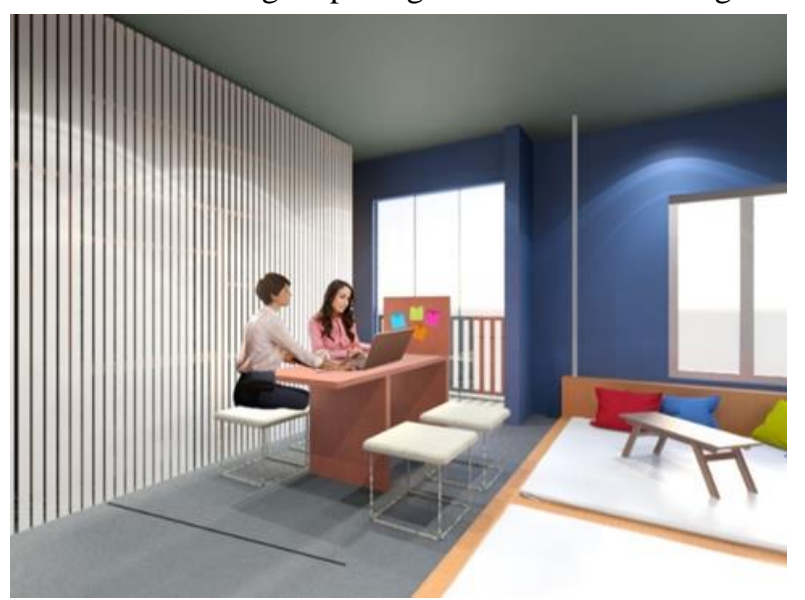

Gambar 7. Perspektif Ruang Bekerja

\section{Mode Ruang Makan}

The smart table, meja ini juga bisa untuk makan malam bersama dan bisa di set untuk kapasitas 2-6 orang.
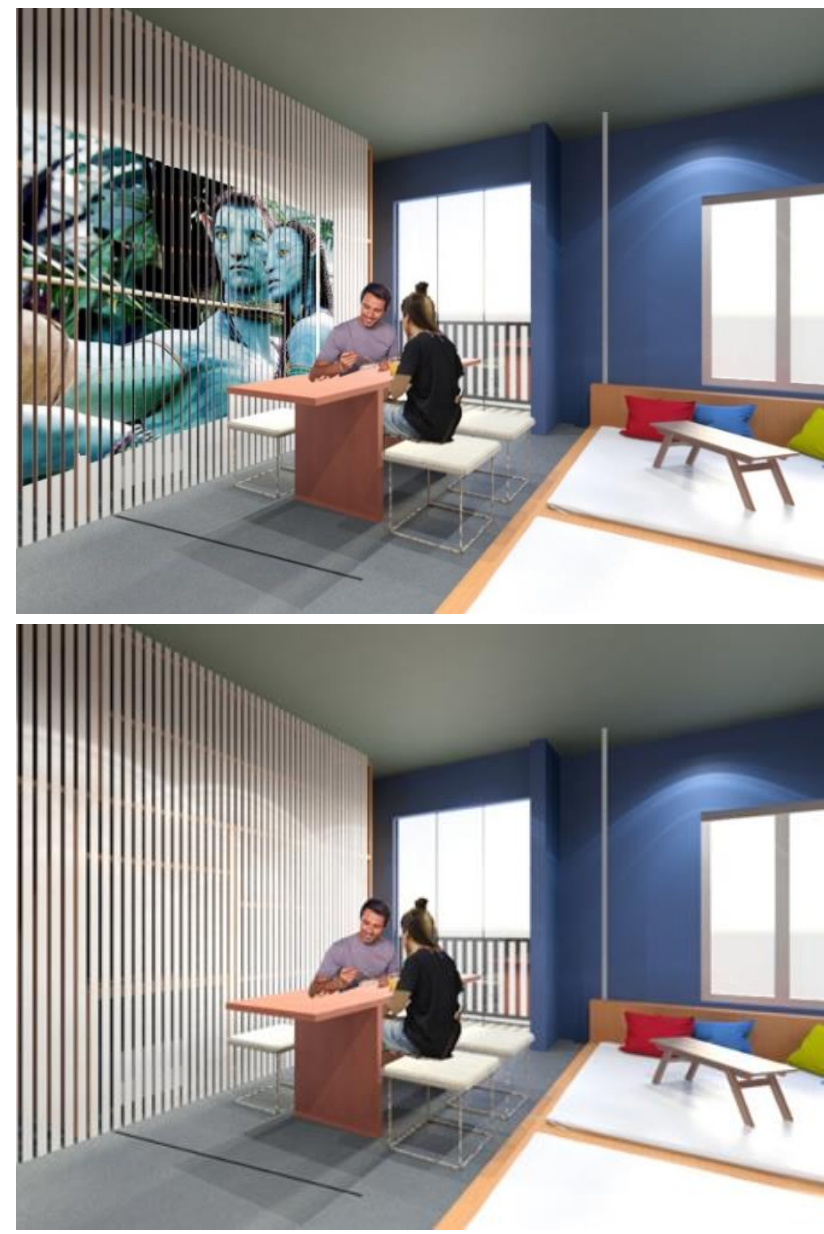

Gambar 8. Perspektif Ruang Makan dengan LED Partition

\section{Mode Privat}

The smart partion, bisa membentuk sebuah private space yang ditujukan kepada user untuk menghindari keramaian mencari ketenangan.

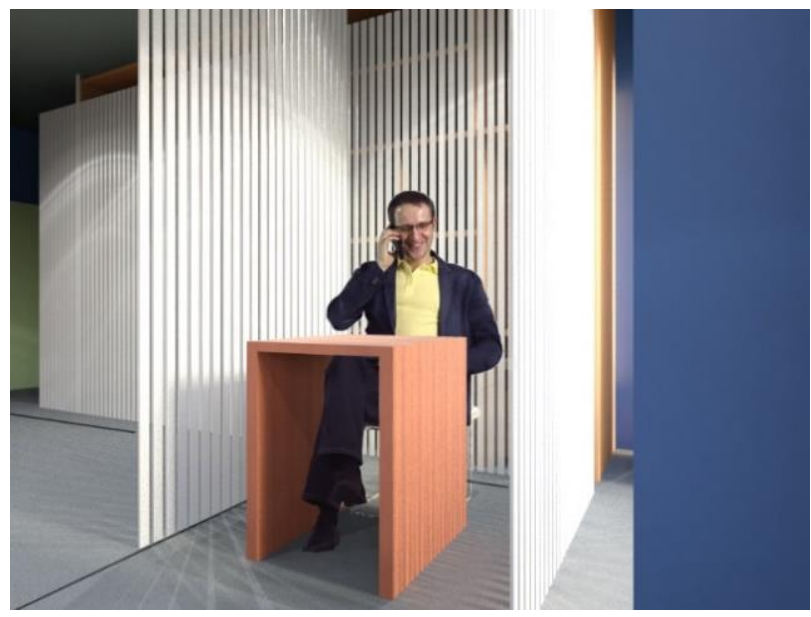

Gambar 9. Pespektif Area Privat 
6. Mode Lounge

Terdapat lounge yang bisa dinaik turunkan, jika digunakan dapat diturunkan,dan berfungsi untuk kegiatan bekerja, bertemu dengan teman - teman, dan bersantai.

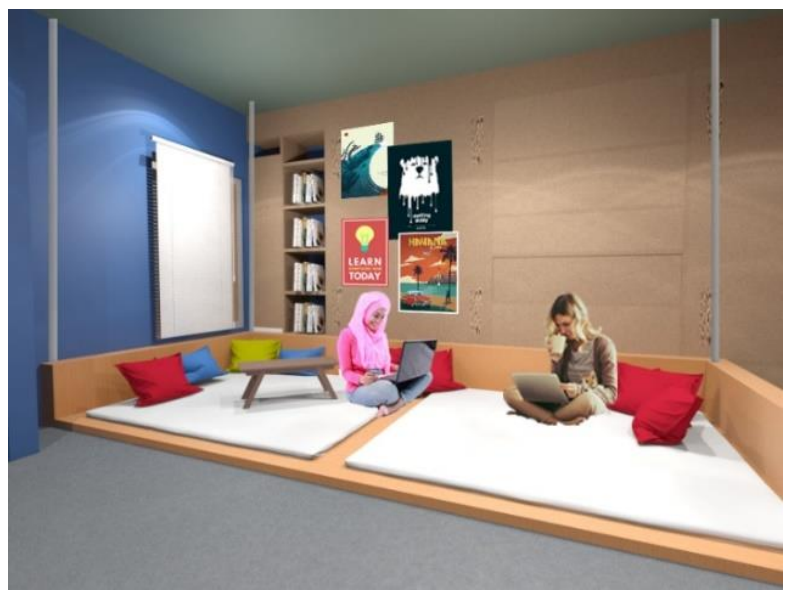

Gambar 10. Pespektif Area Lounge

7. Mode Tempat Penyimpanan

The storage, yang multi fungsi terdapat pada meja yang tersimpan di dalam storage tersebut.

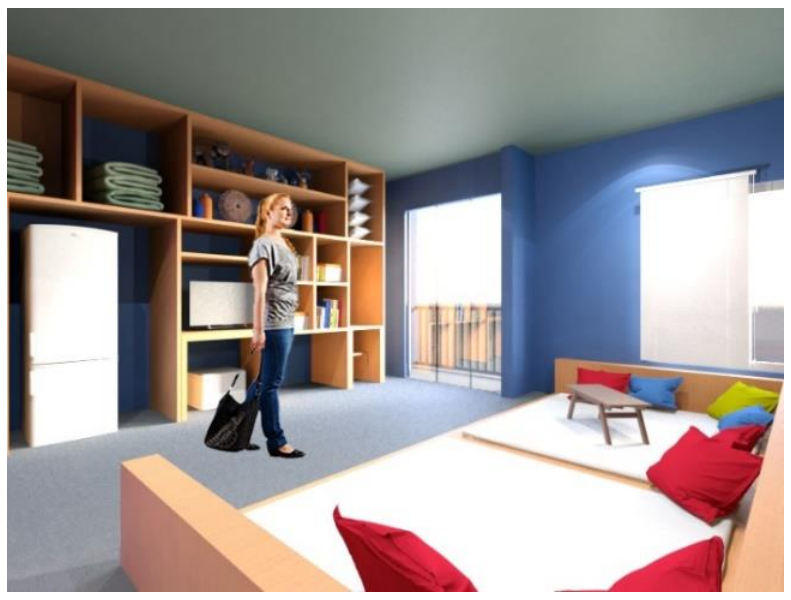

Gambar 11. Pespektif Area Storage

8. Mode Kamar Mandi

Dilengkapi dengan fixutre-fixture green design yang mengunkan grey water untuk membilas toilet, dan shower yang menghemat air.

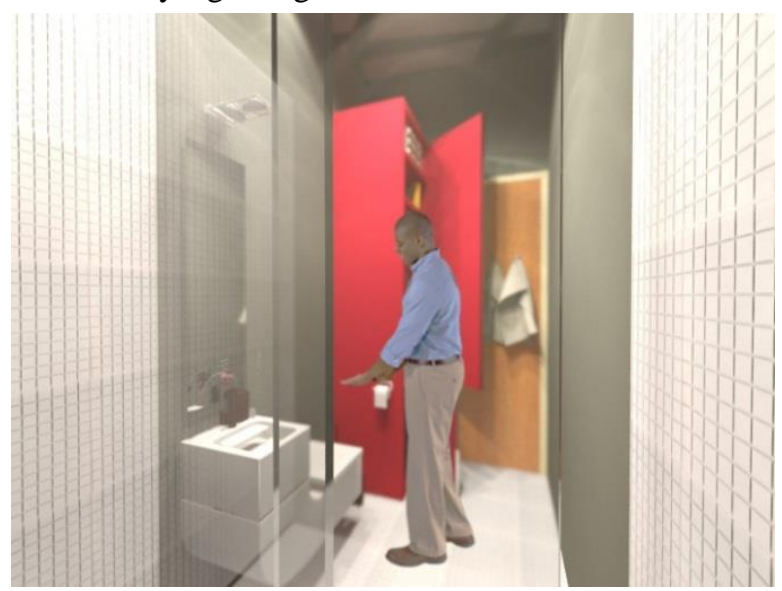

Gambar 12. Pespektif Kamar Mandi
9. Mode Dapur

Dapur yang simple dan terdapat penutup sehingga jika tidak dipakai tidak terlihat sesak.

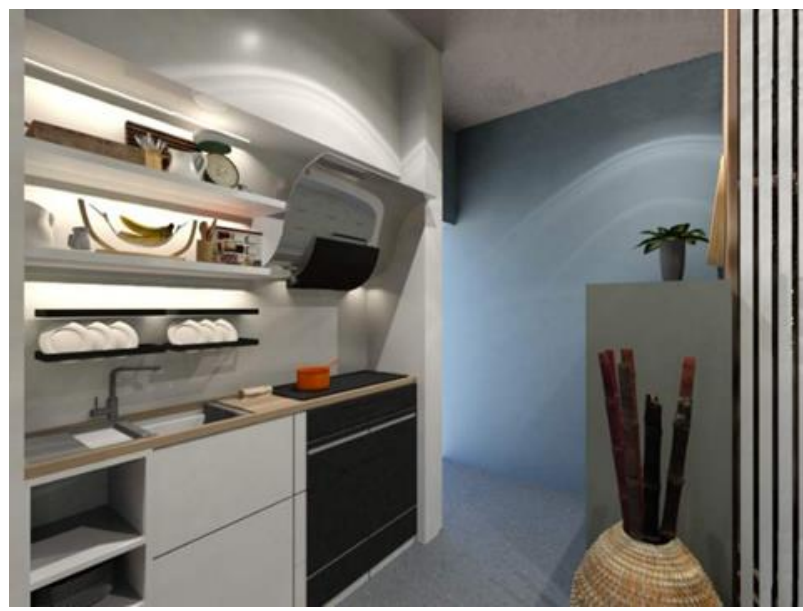

Gambar 13. Pespektif Area Dapur

\section{Pemilihan Warna}

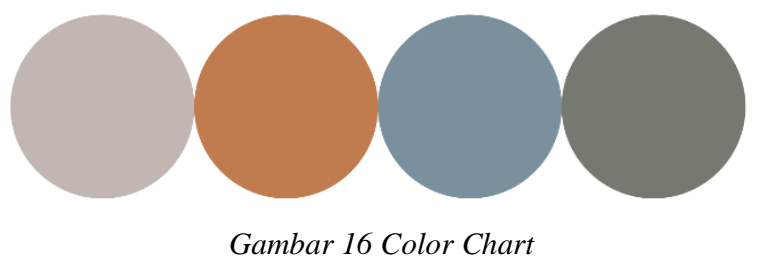

1. Cokelat, menyampaikan keramahan, bahagia, inovasi, energi dan fun! membuat ruangan terasa welcoming. dan menjadi aksen dalam ruangan.

2. Orange, menyampaikan keramahan, bahagia, inovasi, energi dan fun! membuat ruangan terasa welcoming. dan menjadi aksen dalam ruangan.

3. Biru, memberikan efek untuk menstimulasi produktivitas, simbol dari jiwa muda. membuat mood yang ceria, fresh dan tenang. dan membuat ruangan terasa lebih luas.

4. Hijau, menstimulasi harmoni dalam otak dan membuat keseimbangan antara tubuh dengan emosi. memberi efek tenang dan memberi atmosfir yang tenang. juga menyampaikan pertumbuhan, relax, dan keamanan.

\section{Aspek Eco-Interior}

1. Ventilation systems, salah satu kelebihan omahub! apartemen ini memiliki fitur untuk mendapatkan penghawaan alami dengan smart partition dapat membuka pintu kaca lalu diberi partisi sehingga udara dapat masuk dengan tetap menjaga keamanan dan menggunakan AC dengan eco system.

2. Layout penggunaan space yang effisien dan efektif. Memperhatikan kesehatan penghuni didalam.Jika pintu balkon dan pintu masuk apartemen dibuka, dapat terjadi cross ventilation di mana udara lama terganti dengan udara baru sehingga kesehatan pengguna apartemen terjaga.

3. Material, menggunakan material yang sustainable dan low-emission. material utama kayu, cork, concrete. cork bersifat biodegredable dan recycleable, juga dapat 
menjadi peredam suara.concrete membantu efisiensi energi karena dapat menyimpan panas dan juga tidak panas untuk yang tidak terkena sinar matahari. selain itu juga meningkatkan kualitas udara dalam ruangan. dan biaya yang sedikit untuk perawatan.

4. Lighting, menggunakan lampu energy-efficient seperti lampu LED. Memaksimalkan bukaan sehingga pencahayaan pasif (dari sinar matahari).

5. Plumbing Fixture, menggunakan peralatan untuk kamar mandi yang dapat menghemat air lebih banyak dan menggunakan wastafel yang limbah airnya (grey water) dapat digunakan untuk flush toilet.

\section{Teknologi}

1. Smart partition, terdapat partisi yang dapat bergerak dengan terdapat rel dibawahnya. partisi yang dapat merubah fungsi area dari tempat bekerja menjadi ruang tidur. dapat berubah warna menggunakan bahan LED yang dapat membuat suasana ruangan berubah sesuai kebutuhan.

2. Blum motion \& draw hinge, teknologi dalam konstruksi perabot, sehingga pengguna hanya menekan kemudian lemari/perabot akan membukan dengan smooth! yang diterapkan di semua perabot dalam Omahub!

3. Gesture, storage terhubung dengan teknologi gesture dimana individu menggerakan suatu gesture kemudian kursi dalam storage akan keluar secara otomatis

4. Multifunction furniture, penggunaan perabot multifungsi untuk memenuhi kebutuhan aktivitas pengguna apartemen, seperti meja yang dapat diexpand, sebuah kursi yang dapat dirakit menjadi beberapa kursi, lemari baju yang bisa menjadi dinding atau partisi sehingga sejumlah ruang bisa berubah menjadi walk-in closet, dan tempat tidur yang bisa dinaik turunkan untuk menyediakan space lebih luas saat sedang digunakan sebagai tempat kerja.

\section{Kritik Desain}

Pada tahap penjurian langsung, para dewan juri memberikan beberapa masukan untuk meningkatkan kualitas desain. Pertama, keunggulan (fitur teknologi) dalam produk desain Omahub terlalu banyak sehingga calon pengguna tidak menemukan fokus poin jual utama melalui perancangan ini. Kedua, perancangan Omahub ditujukan kepada profesional muda yang mayoritas masih merintis usaha dari bawah. Sedangkan Omahub memiliki berbagai fitur teknologi yang memang mendukung, namun dari segi budget tentu saja dengan teknologi-teknologi tersebut akan membuat biaya sangat tinggi yang pada akhirnya tidak sesuai kemampuan target market.

Melalui kritik desain yang disampaikan oleh dewan juri, para penulis sekaligus para desainer yang merancang melihat kritik tersebut sebagai input yang sangat membangun perancangan ini kedepannya. Sehingga perlunya menentukan fokus utama dari produk Omahub ini. Para penulis sekaligus desainer sudah menemukan keunggulan yang ingin ditonjolkan yaitu adalah menjual suasana apartemen yang seperti "Omah" nyaman. Dan untuk kritikan kedua penulis perlu mencari tahu dan melakukan proses brainstorming agar budget produk Omahub ini dapat sesuai dengan target market yang telah ditetapkan.

\section{SIMPULAN}

Perancangan apartemen dengan konsep Omahub! menjadi alternatif solusi lahan untuk tempat tinggal yang semakin sedikit. Omahub! dengan berbagai kelebihan meliputi smart partition, teknologi gesture, perabot multifungsi, dan disesuaikan dengan budaya orang Indonesia, menjadi small office home office yang cocok bagi profesional muda yang ingin bekerja dan beristirahat di satu tempat.

\section{REFERENSI}

[1] https://nasional.tempo.co/read/1067303/setelah-resmiikut-pemilu-2019-ini-yang-ingin-dilakukan-pbb

[2]https://www.ted.com/talks/kent_larson_brilliant_design s_to_fit_more_people_in_every_city Marlina, Endy. 2008. Panduan Perancangan Bangunan

[3] Ernst Neufert. Data Arsitek Edisi 33 Jilid 1,2 (Jakarta. Erlangga, 1995), Hal 86.

[4] kbbi.kemdikbud.go.id

[5] Komersial. Yogyakarta: ANDI

[6]http://juliokriswinanto94.blogspot.com/2014/09/aplikas i-wlan-untukkebutuhan-soho.html

[7] Beazly, Mitchell. (2001). Making The Most Of Small Spaces. British: Conran Octopus Ltd.

[8] Yuvensius Kevin Constantine dan Adi Santosa .2015. Perancangan Mebel Multifungsi Untuk Home Office. JURNAL INTRA Vol. 3 No. 2 : 163-166

[9] Castells, Manuel. 2004. "Informationalism, Networks, and the Network Society: A Theoretical Blueprint", in The Network Society: A Cross Cultural Perspectives, Ch. 1, pp. 3-48. Cheltenham: Edward Edgar Publishing Ltd.

[10] Miarso,. 2007. Menyemai benih teknologi pendidikan. Jakarta. Pustekom Dinas

[11] Suprobo, Filipus Priyo.’Design Thinking as a Medium of Professionalism and Learning : a Case of Bussiness Incubator. "Cogent Arts \& Humanities 5.1 (2018) : 1458457 